\title{
Intensivist-led care in the COVID-19 pandemic
}

\author{
Marguerite M. Hoyler ${ }^{1}\left[\right.$ ] Briana S. Lui ${ }^{2} \cdot$ Robert S. White ${ }^{1,2}$
}

Received: 29 May 2020 / Accepted: 31 May 2020 / Published online: 8 June 2020

(c) Japanese Society of Anesthesiologists 2020

Keywords COVID-19 · Critical care medicine $\cdot$ Intensivist coverage · AKI · ARDS

To the Editor:

We read with interest the article by Oh and colleagues [1], in which clinical management by intensivists was associated with decreased rates of acute kidney injury (AKI) and shorter durations of mechanical ventilation among postoperative patients in the intensive care unit (ICU). We commend the authors for this outstanding study, which also has urgent implications for the current COVID-19 crisis.

The COVID-19 pandemic has led to a dramatic increase in critically ill patients, primarily due to acute respiratory distress syndrome (ARDS). A high prevalence of AKI has also been observed [2]. The pandemic has strained ICU resources and has led to novel staffing models to help expand attending oversight availability, including at our own institution [3]. In this setting, the clinical impact of intensivist versus non-intensivist oversight of COVID-19 patient care is unknown. However, Oh and colleagues' findings suggest that a shortage of intensivists could have significant adverse effects on clinical outcomes in COVID-19-induced ARDS and AKI.

We recognize that the COVID-19 population is different from the surgical cohort included in the study by $\mathrm{Oh}$ et al. and we caution against inappropriate extrapolation of their data. However, the effect of intensivist-led care on COVID19 clinical outcomes is an urgent subject for further research.

\section{Compliance with ethical standards}

Conflict of interest No competing interests declared.

\section{References}

1. Oh TK, Song IA, Jeon YT. Admission to the surgical intensive care unit during intensivist coverage is associated with lower incidence of postoperative acute kidney injury and shorter ventilator time. J Anesth. 2019;33(6):647-55.

2. Ronco C, Reis T, Husain-Syed F. Management of acute kidney injury in patients with COVID-19. Lancet Respir Med. 2020. https ://doi.org/10.1016/S2213-2600(20)30229-0.

3. Kumaraiah D, Yip N, Ivascu N, Hill L. Innovative ICU physician care models: Covid-19 pandemic at New York-Presbyterian. NEJM Catal Innov Care Deliv. 2020. https://doi.org/10.1056/ CAT.20.0158.

Publisher's Note Springer Nature remains neutral with regard to jurisdictional claims in published maps and institutional affiliations.

This comment refers to the article available online at https://doi. org/10.1007/s00540-019-02684-8.

\section{Marguerite M. Hoyler}

mam9508@nyp.org

1 Department of Anesthesiology, New York Presbyterian Hospital-Weill Cornell Medical Center, 525 East 68th Street, New York, NY 10065, USA

2 Center for Perioperative Outcomes, Department of Anesthesiology, New York Presbyterian Hospital-Weill Cornell Medical Center, New York, NY, USA 